Rapid Reviews COVID-19

\title{
Reviews of "A handheld point-of-care system for rapid detection of SARS- CoV-2 in under 20 minutes"
}

Julia Schaletzky ${ }^{1}$, Celine Perier ${ }^{2}$

${ }^{1}$ UC Berkeley, ${ }^{2}$ CEND - UC Berkeley

Published on: Aug 11, 2020

DOI: $10.1162 / 2$ e3983f5.2e5ce668

License: Creative Commons Attribution 4.0 International License (CC-BY 4.0). 
To read the original manuscript, click the link above.

Summary of Reviews: The portable diagnostic platform presented is an indispensable molecular diagnostic solution for COVID-19. Built with secure cloud connectivity, it can enable real-time case identification and epidemiological surveillance. Comparisons are needed.

\title{
Reviewer 1 (Julia Schaletzky)
}

Reviewer 2 (Celine Perier) |

\author{
RR:C19 Strength of Evidence Scale Key \\ प्रमप = Misleading

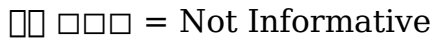 \\ प्रा पि = Potentially Informative

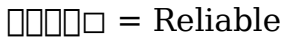 \\ प्राप्र = Strong
}

To read the reviews, click the links below. 